\title{
Percepção dos professores de educação física e pedagogia com relação à ludicidade no processo de ensino e aprendizagem
}

\author{
João Paulo da Silva Maciel*
}

\section{Resumo}

O objetivo do presente texto foi de analisar a percepção dos professores de Educação Física e Pedagogia com relação à ludicidade no processo de ensino e aprendizagem decrianças na educação infantil. Sendo assim esta pesquisa foi realizada por meio de um levantamento de abordagem quantitativa e qualitativa, de campo, pelo método descritivo exploratório com delineamento de corte transversal. A amostra foi constituída de $(n=12)$ professores de Educação Física e Pedagogia. Foi utilizado como instrumentos um questionário sociodemográfico e um questionário estruturado elaborado pelo orientador e pesquisador, contendo alguns dados pessoais e informações sobre o estudo. Conclui-se que a ludicidade nas aulas da Educação da Infantil é de suma importância no desenvolvimento da criança, pois através das atividades lúdicas e recreativas aplicadas, consegue ajudar a desenvolver o ensino e aprendizagem da criança, como também os aspectos cognitivos, afetivos e motores.

Palavras-chave: Educação Física; Pedagogia; Professores; Ludicidade; Educação Infantil.

https://orcid.org/0000-0003-4552-2841

Centro Universitário Doutor Leão Sampaio. Graduado em Educação Física. Centro Universitário Doutor Leao Sampaio, Juazeiro do Norte, Ceará. jp.ed.fisica2015@outlook.com 


\section{Perception of teachers of physical education and pedagogy in relation to ludicity in the teaching and learning process.}

\section{Abstract}

The aim of this text was to analyze the perception of physical education and pedagogy teachers regarding the ludicity in the teaching and learning process of children in early childhood education. Thus, this research was carried out through a survey of quantitative and qualitative approach, field, by the exploratory descriptive method with cross-sectional design. The sample consisted of $(n=12)$ teachers of Physical Education and Pedagogy. A sociodemographic questionnaire and a structured questionnaire elaborated by the advisor and researcher were used as instruments, containing some personal data and information about the study. It is concluded that the ludicity in the classes of Early Childhood Education is of paramount importance in the child's development, because through the recreational and recreational activities applied, it can help develop the teaching and learning of the child, as well as the cognitive, affective and motor aspects. Keywords: Physical Education; Pedagogy; Teachers; Ludicity; Early Childhood Education.

\section{Percepción de los profesores de educación física y pedagogía en relación con la ludicidad en el proceso de enseñanza y aprendizaje}

\section{Resumen}

El objetivo de este texto fue analizar la percepción de los profesores de educación física y pedagogía sobre la ludicidad en el proceso de enseñanza y aprendizaje de los niños en la educación de la primera infancia. Así, esta investigación se llevó a cabo a través de una encuesta de abordaje cuantitativo y cualitativo, de campo, por el método descriptivo exploratorio con diseño transversal. La muestra estuvo constituida por $(n=12)$ profesores de Educación Física y Pedagogía. Se utilizaron como instrumentos un cuestionario sociodemográfico y un cuestionario estructurado elaborado por el asesor y el investigador, conteniendo algunos datos personales e informaciones sobre el estudio. Se concluye que la ludicidad en las clases de Educación Infantil es de suma importancia en el desarrollo del niño, ya que a través de las actividades recreativas y recreativas aplicadas, puede 
ayudar a desarrollar la enseñanza y el aprendizaje del niño, así como los aspectos cognitivos, afectivos y motores.

Palabras clave: Educación Física; Pedagogía; Profesores; Ludicidad; Educación Infantil Temprana.

\section{Introdução}

O tema a ser abordado neste estudo tem como propósito discutir a contribuição da ludicidade enquanto prática pedagógica, podendo atuar desta forma para o processo de ensino e de aprendizagem de crianças na educação infantil e, assim, estabelecer uma relação entre métodos educativos que são vivenciadas nas demais áreas do conhecimento trabalhadas nas aulas da Educação Infantil nasescolas.

Portanto, a ludicidade como conteúdo desenvolvido na Educação Infantil, tem se tornado um instrumento de grande importância para o processo de ensino e de aprendizagem da criança, ou seja, atua como um método de formação, auxiliando no aprendizado através do movimento e da recreação lúdica, sendo assim, ao trabalhar com a criança, percebe-se que ela apresenta várias dificuldades motoras e cognitivas, em seus primeiros anos de vida e quando entra na fase escolar (DALLABONA; MENDES, 2015).

Desde modo, a ludicidade na primeira infância é um instrumento preciso para incentivar a prática do movimento em todas as etapas de sua vida. Sua existência está fundamentada na necessidade de formar as gerações mais novas, ensinando-lhes seus conhecimentos, valores e crenças e, com isso, dando-lhes possibilidades para novas realizações (PAIANO, 2006, LEITE; SILVA, 2015).

Compreende-se então, que a Educação Física e a Pedagogia são áreas de formação que tem um papel fundamental na Educação Infantil, pela possibilidade de proporcionar às crianças uma diversidade de experiências através de situações nas quais elas possam criar inventar, descobrir movimentos novos, reelaborar conceitos e ideias sobre o movimento e suas ações (BARBOSA, 2007).

Desde que a escola existe como instituição, vários programas pedagógicos têm sido propostos, apesar da variedade de programas encontrados, que refletiram diferentes funções da escola ao longo 
de sua história, atualmente, é reconhecido que a escola tem papel essencial no desenvolvimento das crianças e sua função social é bastante importante, devido à necessidade crescente das famílias de compartilharem com as instituições os cuidados com seus filhos, ou seja, tem uma função política clara, contribuindo para a formação dos cidadãos (FERRAZ, 1996; DALLABONA; MENDES, 2015).

Além disso, é um espaço para que, através de situações de experiências com o corpo, com materiais e de interação social, as crianças descubram os próprios limites, enfrentem desafios, conheçam e valorizem o próprio corpo, relacionem-se com outras pessoas, percebam a origem do movimento, expressem sentimentos, utilizando a linguagem corporal, localizem-se no espaço, entre outras situações voltadas ao desenvolvimento de suas capacidades intelectuais e afetivas, numa atuação consciente e crítica (BARBOSA, 2001; DALLABONA; MENDES, 2015). Dessa forma, essas áreas do conhecimento poderão contribuir para a efetivação de um programa de Educação Infantil, comprometido com os processos de desenvolvimento da criança e com a formação de sujeitos emancipados (BETTI, 2018; SILVA, 2004).

Cada vez mais tem se tornado evidente que o crescimento da criança é um aspecto que deve ser observado constantemente pelos professores, sendo assim, possível analisar e perceber como ocorre o processo de desenvolvimento da criança nos estágios iniciais da infância, pois é a partir desta concepção que o professor poderá identificar e perceber como trabalhar o desenvolvimento motor da criança (GALLARDO, OLIVEIRA; ARAVENA, 2018).

A aprendizagem de qualquer habilidade motora requer a seleção de informações que podem estar contidas no meio ambiente e/ou fornecidas pelo professor. Para que esta informação seja retida, para posterior interpretação e possível armazenamento na memória de longa duração, o processo da atenção é fundamental(SOUSA; SILVA, 2017).

Deste modo, esta pesquisa justifica-se pela escassez em investigar sobre a ludicidade no processo de ensino e de aprendi- 
zagem de crianças na Educação Infantil. Sendo assim, o presente estudo tem como problemática: Será que a ludicidadeexerce influência no processo de ensino e aprendizagem de crianças na Educação Infantil? Qual a percepção dos professores de Educação Física e Pedagogia, com relação a este conteúdo aplicado a crianças na Educação Infantil, ou seja, sua pratica pode ajudar no desenvolvido do aluno e influenciar no processo de ensino e aprendizagem?

Mediante estas constatações o presente estudo tem como objetivo geral: Analisar a percepção dos professores de Educação Física e Pedagogia com relação à ludicidade no processo de ensino e aprendizagem de crianças na Educação Infantil.

Conforme o objetivo geral do estudo e com base na proposta de pesquisa, os objetivos específicos foram: Investigar como os professores de Educação Física e Pedagogia em suaspráticas pedagógicas utilizam o lúdico como recurso metodológico; Identificaras contribuições da ludicidade para o desenvolvimento e aprendizado da criança em seus diversos aspectos, como também verificar como é concebido a ludicidade e a sua importância no contexto da Educação Infantil.

\section{Materiais e métodos}

A presente pesquisa quanto à sua natureza, foi realizada por meio de um levantamento da abordagem quantitativa e qualitativa, utilizando como base a pesquisa de campo, pelo método descritivo exploratório, tendo como delineamento aspecto relacionado ao corte transversal.

A população foi constituída por professores de educação físicae pedagogia do ensino fundamental e infantil da rede publica municipal no município de Milagres; Missão Velha; Barbalha e Jardim, no estado do Ceará.

A amostra foi constituída de $(n=12)$ professores de educação Física e Pedagogia, composta por $(n=06)$ professores formados em Educação Física, $(\mathrm{n}=04)$ professores do sexo masculino e $(n=02)$ professores do sexo feminino, com faixa etária de idade 
de 36 $\pm 12,0$. Foram pesquisados também $(\mathrm{n}=06)$ professores formados em Pedagogia, todos do sexo feminino, com faixa etária de idade de 35 $\pm 5,0$, como demonstradona tabela abaixo.

Tabela 01: Analise descritiva das variáveis:sexo, em frequência e percentual estratificada por gênero.

\begin{tabular}{c|c|c|c|c}
\hline Formação Específica & \multicolumn{2}{|c|}{ Feminino } & \multicolumn{2}{c}{ Masculino } \\
\hline & & & & \\
\cline { 2 - 5 } & Freq. & $\%$ & Freq. & $\%$ \\
\hline & & & & \\
\hline Educação Física & 02 & $33,3 \%$ & 04 & $66,7 \%$ \\
\hline Pedagogia & 06 & $100,0 \%$ & 00 & $0,0 \%$ \\
\hline & & & & \\
\hline
\end{tabular}

Fonte: Pesquisa 2019.

Os participantes foram selecionados probabilisticamente a partir da amostragem não proporcional por conveniência e intencional. A amostragem não probabilística por conveniência leva em consideração que a seleção da unidade amostral pesquisada é mais facilmente acessível (MARCONI; LAKATOS, 2010). Já a intencional mostra que os indivíduos são selecionados de modo a ser mais próximo do valor médio das variáveis da população (THOMAS; NELSON, 2002).

Foram adotados como critérios de inclusão: responder a todas as perguntas do questionário sociodemográfico e sobre a temática pesquisada. Os critérios de exclusão foram: recusar participar da pesquisa, não responder a uma das perguntas do questionário sociodemográfico e sobre a temática pesquisada e não estar presente no dia da aplicação do questionário.

Os instrumentos utilizados na pesquisa foram um questionário sociodemográfico, contendo alguns dados pessoais; e um questionário estruturado, elaborado pelo orientador e pesquisador, com o intuito de analisar a importância da ludicidade no processo de ensino aprendizagem de crianças na educação infantil. Este estudo 
apresentou como variáveis relacionadas ao o perfil sociodemográfico dos professores tais como: sexo (Masculino e Feminino), idade (quantidade de anos de vida completos autoreferido), ano de formação e tempo de atuação profissional.

O questionário estruturado continha 07 questões fechadas, 06 (Seis) questões com escore de classificação (Nunca; Raramente; Quase Sempre e Sempre), 01 (uma) questão sendo equivalentes as escalas (Sem importância; Importante; Relativamente importante e Muito Importante) e 01 (Uma) questão aberta sobre a concepção do professor em relação à ludicidade.

Os procedimentos metodológicos da presente pesquisa constituíram-se dentro dos padrões éticos legais referentes à pesquisa com seres humanos da resolução 446/12. A conformidade da proposta da pesquisa foi submetida para apreciação no comitê de ética em pesquisa do Centro Universitário Dr. Leão Sampaio sendo aprovado sob o parecer de numero 1.011.144. Para a realização da pesquisa, foi feito contato com os professores nas respectivas instituições de ensino/escola, com intuito de obter informações referentes aos elementos que fizeram parte da pesquisa.

Posteriormente foram realizadas visitas nas escolas para estabelecer contato com a população e assim possível aplicar os questionários, mediante a assinatura do termo de consentimento livre e esclarecido (TCLE), ficando livre a opção por participar, podendo o sujeito desistir a qualquer momento se assim desejar.Todos os participantes ficaram com uma cópia do termo para o caso de desejarem realizar contato com o pesquisador em função de dúvidas ou desistência.

Os dados deste estudo foram analisados por meio de distribuição das resposta por meio da elaboração de uma tabela com cada informação fornecida pelo professor e as informações tabuladas de acordo com a estatística descritiva, sendo distribuídos e apresentados em forma de gráficos e tabelas de frequência a partir do software Excel for Windows da Microsoft Office 2007, como também a distribuição de frequência, através do programa SPSS 20.0. 


\section{Resultados e discussões}

Os dados referentes aos resultados desta pesquisa, abrangendo a coleta de dados e análise dos mesmos, foram realizados no ano de 2019, tabulados separadamente e, posteriormente, foram criados tabelas para uma melhor interpretação dos dados.

Tabela 02: Analise descritiva das variáveis idades, ano de formação e tempo de atuação em valores mínimo, máximo, media e desvio padrão estratificada por gênero.

\begin{tabular}{|c|c|c|c|c|c|c|c|c|}
\hline Variáveis & \multicolumn{4}{|c|}{ Feminino } & \multicolumn{4}{|c|}{ Masculino } \\
\hline & Mín. & Máx. & Média & $\mathrm{dp}$ & Mín. & Máx. & Média & $\mathrm{dp}$ \\
\hline Idade & 28 & 45 & 35 & 5,0 & 25 & 53 & 36 & 12,0 \\
\hline $\begin{array}{c}\text { Ano Forma- } \\
\text { ção }\end{array}$ & 1991 & 2014 & 2007 & 8,0 & 2006 & 2012 & 2009 & 2,0 \\
\hline $\begin{array}{c}\text { Atuação } \\
\text { profissional }\end{array}$ & 1,0 & 18,0 & 11,0 & 6,6 & 5,0 & 9,0 & 6,3 & 1,9 \\
\hline
\end{tabular}

$*$ Min. $=$ Mínimo $-*$ Máx. $=$ Máximo $-* \mathrm{X}=$ Média $-* \mathrm{dp}=$ Desvio Padrão. Fonte: Pesquisa 2019.

De acordo com a tabela 02, o estudo caracteriza a amostra conforme os valores das medidas estatísticas descritivas de (mínimo, máximo, média e o desvio padrão) das respectivas variáveis analisadas em ambos os sexos.

Com relação à variável idade, foi observado que a média de idades dos professores do sexo masculino foi de 36,0 $\pm 12,0$. Na variável ano de formação, o menor ano de formação foi $(a n o=2006)$ e o maior ano de formação foi em $(a n o=2012)$. Para a variável correspondente ao tempo de atuação foi possível observar que o menor tempo de atuação foi de $(a n o=05)$ e o maior tempo de atuação foi de $($ ano $=09)$.

Entretanto, para o sexo feminino a média de idade foi de $35,0 \pm 5,0$, seguindo a mesma descrição relativa à variável ano de formação, o menor ano de formação para o gênero feminino foi 
$(a n o=1991)$ e o maior ano de formação foi em (ano=2014). Para a variável correspondente ao tempo de atuação foi possível observar que o menor tempo de atuação foi de $(a n o=01)$ e o maior ano de atuação foi de $(a n o=18)$.

Pode-se constatar que entre a faixa etária de idade, os professores do gênero feminino obtiveram uma média de idade maior do que os professores do gênero masculino. Com relação ao tempo de atuação é notável que os professores do gênero feminino estão a mais tempo atuando na área de docência, quando comparado com os professores do gênero masculino.

Conforme estes achados, foi observado que o professor tem papel primordial nesse contexto, pois será ele o mediador, o organizador do tempo, das atividades, do espaço, das certezas e incertezas do dia a dia da criança em seu processo de construção de conhecimento. É ele também que vai criar e recriar sua proposta político-pedagógica e para que ela seja concreta, crítica, dialética este educador deve ter competência técnica para fazê-la (IGNACHEWSKI, 2003). (Tabela 3).

Partindo das manifestações dos professores, foi possível montar uma tabela de convergência de maneira que auxiliasse, não apenas na visualização de suas opiniões obtidas, mas também, na compreensão do problema em questão.

Nota-se com respostas dos professores formados em Educação Física a sua concepção em relação a respeito da Ludicidade e sua importância na Educação Infantil. Em meio a suas respostas, pode-se observar que a ludicidade tem sua importância, para o desenvolvimento da criança, sendo que na maioria das opiniões obtidas, os mesmos relataram que são vários os benefícios que a pratica recreativa e as atividades lúdicas podem acarretar no desenvolvimento da criança.

Com este estudo pode-se observar que a Ludicidade utilizada como instrumento recreativo por meio dos professores, pode possibilitar a identificação e a descrição das concepções de ludicidade que um grupo de professores desenvolve nas aulas da Educação Infantil em escolas da rede municipal das cidadesde Milagres; Missão Velha; Barbalha e Jardim, no estado do Ceará. 
Tabela 03: Analise qualitativa referente às opiniões dos professores formados em Educação Física.

\begin{tabular}{|c|c|}
\hline Variável & Respostas por professores \\
\hline \multirow{6}{*}{$\begin{array}{l}\text { Qual a sua con- } \\
\text { cepção a respeito } \\
\text { da Ludicidade e } \\
\text { sua importância na } \\
\text { educação infantil? }\end{array}$} & $\begin{array}{l}\text { Professor 01: É uma Atividade livre, educativa, onde em sua } \\
\text { participação. A criança vivencia momentos de alegria, interação } \\
\text { e prazer. A ludicidade e de fundamental importância na vida da } \\
\text { criança, pois além de proporcionar prazer e diversão, desenvolve } \\
\text { suas habilidades motoras, cognitivas e afetivas, que vão } \\
\text { desencadeando o seu aprendizado. }\end{array}$ \\
\hline & $\begin{array}{l}\text { Professor 02: A ludicidade é uma técnica metodológica, na } \\
\text { aprendizagem de forma mais prazerosa. Tendo como objetivo } \\
\text { analisar as técnicas lúdicos no processo de ensino aprendizagem } \\
\text { na educação infantil garantindo conhecimentos da realidade, vi- } \\
\text { venciadas, levando o individuo a socialização. }\end{array}$ \\
\hline & $\begin{array}{l}\text { Professor 03: É muito importante, pois é a traves do lúdico que } \\
\text { a criança, aprende e também para o desenvolvimento de cada um. }\end{array}$ \\
\hline & $\begin{array}{l}\text { Professor 04: A ludicidade é essencial para a formação das crian- } \\
\text { ças, pois o ensino lúdico, através das brincadeiras, aprende melhor } \\
\text { e se desenvolvem nos aspectos motores, intelectuais e sócias. }\end{array}$ \\
\hline & $\begin{array}{l}\text { Professor 05: Momento de prazer e alegria, vivenciado pelas } \\
\text { crianças, por meios dos jogos, e das brincadeiras, sua importância } \\
\text { esta no fato em desenvolver os aspectos motores, cognitivos e } \\
\text { afetivos da criança. }\end{array}$ \\
\hline & $\begin{array}{l}\text { Professor 06: A ludicidade é de suma importância, para o desen- } \\
\text { volvimento da criança, onde a partir do lúdico, forma-se valores, } \\
\text { costumes, despertando o prazer e o gostar das brincadeiras popu- } \\
\text { lares, além de trabalhar todas as suas habilidades. }\end{array}$ \\
\hline
\end{tabular}

Fonte: Pesquisa 2019.

O estudo aponta que o trabalho lúdico nas instituições de ensino, além de interessante na visão desses professores está intimamente ligada à presença de recursos materiais, tais como brinquedos, para que se promova a ludicidade nas aulas ao invés do próprio desenvolvimento do imaginário infantil enquanto elemento fomentador de situações lúdicas.

Mediante estes achados, nota-se que a ludicidade tem ganhado destaque tanto no âmbito escolar quanto na Educação Infantil, 
pois a mesma é a responsável pelo auxílio no processo de aprendizagem dos educandos, sendo os jogos e as brincadeiras muito utilizados como prática pedagógica, estimulando o desenvolvimento de forma prazerosa e criativa (GRILO, 2015; SOUSA; SILVA, 2017).

Em um estudo realizado com professores do Rio de Janeiro, para o qual foi pesquisado sobre quais aspectos a ludicidade tinha influência e sobre a importância que a prática proporcionava para Educação Infantil, pode-se observar que a ludicidade traz diversas possibilitase situações de aprendizagem que contribuem em sua grande parte e ajuda no desenvolvimento integral da criança, mas deve haver uma dosagem entre a utilização do lúdico instrumental. Isto é, é necessário mesclar a brincadeira com a finalidade de atingir objetivos escolares, e também a forma de brincar espontaneamente, envolvendo o prazer e o entretenimento, neste último, o lúdico é essencial (SPIGOLON, 2006; MEINHARDT, 2016). (Tabela 4).

Em meio às respostas dos professores formados em Pedagogia, observa-se o lúdico com viés instrumental nas respostas acima citadas, como demonstra a tabela 04 . Foi percebido, mediante os achados, que o lúdico não é usado somente como meio para ensinar algo, em cada uma das respostas citadas, nota-se que existe até mesmo a preocupação quanto à alfabetização já na Educação Infantil.

Neste aspecto é importante ressaltar que, ao se referir sobre a contribuição do lúdico para o desenvolvimento e aprendizagem da criança, existe uma forte presença de como o ensino lúdico ajuda na prática pedagógica dos entrevistados, como se percebe-se nas respostas dos professores com formação em Pedagogia.

Nota-se com as respostas dos professores que a ludicidade tem um papel essencial na formação de hábitos e atitudes, no desenvolvimento cognitivo, motor e afetivo da criança, como também na contribuição do desenvolvimento e da aprendizagem da criança por meio das atividades recreativas. No entanto, a educação moral torna-se um conteúdo pedagógico a ser trabalhado com a criança da Educação Infantil, mas numa proposta crítica, uma vez que os entrevistados consideram o educador como mediador e não 
um mero transmissor de normas e valores a serem incubados na criança. Sendo assim, através do brincar a criança pode desenvolver hábitos e atitudes tendo o professor como mediador (ROMPKOVSKI; SILVA, 2003; SALOMÃO; MARTINI, 2007).

\author{
Tabela 04: Analise qualitativa referente às opiniões \\ dos professores formados em Pedagogia.
}

\begin{tabular}{|c|c|}
\hline Variável & Respostas por professores \\
\hline & $\begin{array}{l}\text { Professor 01: E de uma importância muito relevante, pois a crian- } \\
\text { ça começa a aprender brincando, com jogos, desenvolvendo assim } \\
\text { sua coordenação motora, cognitiva e afetiva. Auxiliando no desen- } \\
\text { volvimento das praticas pedagógicas. }\end{array}$ \\
\hline & $\begin{array}{l}\text { Professor 02: A educação infantil constitui-se em um espaço de } \\
\text { aprendizagem, que busca favorecer os desenvolvimentos de habi- } \\
\text { lidade psicomotores, sociais afetivos e intelectuais da criança. O } \\
\text { lúdico na educação infantil pode ser trabalhado em todas as ativida- } \\
\text { des, pois é uma maneira de aprender e ensinar, despertando o gosto } \\
\text { e o prazer, sendo assim a metodologia de ensino, torna-se amplas } \\
\text { em todos os sentidos. }\end{array}$ \\
\hline
\end{tabular}

Qual a sua concepção a respeito da Ludicidade e sua importância na Educação Infantil?
Professor 03: As atividades lúdicas são fundamentais, para o desenvolvimento físico, cognitivo, social e psicomotor da criança, pois a partir delas a criança poderá se desenvolver melhor.

Professor 04: É um método utilizado para estimular a construção do conhecimento, através das brincadeiras. Sendo de fundamental importância para o aluno vivenciar situações, problemas, atividades físicas e mentais, que venham favorecer a sociabilidade e o desenvolvimento cognitivo, social, cultural e afetivo.

Professor 05: Quando pensamos em alfabetização, entendemos a necessidade de realização de trabalho lúdico, que favorece o processo de alfabetizar letrando. Nesse período a criança precisa, estar perto do que é prazeroso, facilitando a complexidade do conhecimento, favorecendo uma formação mais critica da criança.

Professor 06: $O$ verdadeiro sentido da ludicidade trás vantagens sociais, cognitivas e afetivas da criança, ajudando-as no seu desenvolvimento em relação à sociedade, a criança estimulada de forma ampla e contextualizada, por meio da exploração do meio ambiente, tem mais chances de praticar as atividades motoras e consequentemente de domina-las com facilidade.

Fonte: Pesquisa 2019. 
De acordo com Freire (1997, p. 112), “a criança é uma especialista em brinquedo, mais até que a própria professora. Não uma especialista em teorizar sobreo brinquedo, mas em brincar".

O resgate do universo cultural infantil é o ponto de partida para a construção desituações lúdicas enriquecedoras para as crianças, o lúdico deve ser contemplado naspropostas pedagógicas da Educação Infantil e, numa perspectiva não utilitária apenas,possibilitar experiências reflexivas e significativas uma vez que envolve emoção,participação, prazer, descobertas, entre outros como menciona(KRAMER, 2009; IGNACHEWSKI, 2003).

Neste aspecto torna-se essencial que o professor não confunda o lúdico com "passatempo", pois, conforme menciona Freire (1997), isso equivale a camuflar o problema, e não a ter coragem de lidar com ele. Do ponto de vista educacional, seria como dar água a quem não tem sede, ou seja, brincar é muito mais que isto.

Borba (2016) afirma que é importante os educadores estarem atentos para o fato de que as crianças facilmente dão preferência ao lúdico essencial. Se bem analisado, a criança brincando terá oportunidades de desenvolver capacidades indispensáveis como afetividade, concentração e até mesmo habilidades psicomotoras onde serão explorados diferentes aspectos especiais, sendo eles nos jogos, nas atividades lúdicas e nas brincadeiras. Neste ponto, a criança constrói uma relação com o lúdico através de interações sociais, aprendendo a participar ativamente nas atividades propostas e observar o que está sendo apresentado através do domínio do seu próprio corpo.

Diante dos fatos e informações acima citados, nota-se que, cada vez mais vem sendo discutido sobre a importância do lúdico na aprendizagem e no desenvolvimento da criança, sendo por sua vez, o brinquedo o responsável pela caracterização da infância, proporcionando assim a produção do conhecimento, bem como a aprendizagem, abrangendo o desenvolvimento social, pessoal e cultural do indivíduo (SALOMÃO; MARTINI, 2007). 
Tabela 05:Analise descritiva das variáveis das referentes

à importância da ludicidade no desenvolvimento da criança, exposta em percentual.

\begin{tabular}{l|c|c|c}
\hline \multicolumn{1}{|c|}{ Variáveis } & Formação & Categorias & $\%$ \\
\hline \multicolumn{3}{|c}{} \\
\hline $\begin{array}{l}\text { Na sua atuação, você vê importância da } \\
\text { Ludicidade no trabalho realizado com as } \\
\text { crianças? }\end{array}$ & Educação Física & Sim & $100,0 \%$ \\
\cline { 2 - 4 } & Pedagogia & Sim & $100,0 \%$ \\
\hline
\end{tabular}

\begin{tabular}{l|c|c|c}
\hline Os jogos recreativos e lúdicos dentro das & Educação Física & $\operatorname{Sim}$ & $100,0 \%$ \\
\cline { 2 - 4 } $\begin{array}{l}\text { aulas contribuem para o desenvolvimento } \\
\text { motor, cognitivo e afetivo das crianças? }\end{array}$ & Pedagogia & $\operatorname{Sim}$ & $100,0 \%$ \\
\hline
\end{tabular}

\begin{tabular}{l|c|c|c}
\hline Como você classificaria os jogos lúdicos e \\
$\begin{array}{l}\text { as atividades recreativas enquanto conteú- } \\
\text { do para as aulas na educação infantil? }\end{array}$ & Educação Física & $\begin{array}{c}\text { Muito Im- } \\
\text { portante }\end{array}$ & $100,0 \%$ \\
\cline { 2 - 4 } & Pedagogia & $\begin{array}{c}\text { Muito Im- } \\
\text { portante }\end{array}$ & $100,0 \%$ \\
\hline
\end{tabular}

\begin{tabular}{|c|c|c|c|}
\hline \multirow{2}{*}{$\begin{array}{l}\text { A ludicidade e recreação como conteúdo } \\
\text { das aulas dentro das escolas pode acarretar } \\
\text { benefícios para o desenvolvimento do ensi- } \\
\text { no e aprendizagem da criança? }\end{array}$} & Educação Física & Sempre & $100,0 \%$ \\
\hline & $\mathrm{Pe}$ & Sempre & $100,0 \%$ \\
\hline
\end{tabular}

\begin{tabular}{l|c|c|c}
\hline Quanto à importância da prática da Ludici- & Educação Física & Sempre & $100,0 \%$ \\
\cline { 2 - 4 } $\begin{array}{l}\text { dade dentro da escola, você considera im- } \\
\text { portante o seu ensino como conteúdo das } \\
\text { aulas da Educação infantil. }\end{array}$ & Pedagogia & Sempre & $100,0 \%$ \\
\hline
\end{tabular}

* $\%=$ Percentual

Fonte: Pesquisa 2019.

De acordo com a tabela 05 , pode-se observar que $100 \%$ dos professores afirmaram que "Sim", que a ludicidade tem grande importância no desenvolvimento da criança, como também os jogos recreativos e lúdicos contribuem para o desenvolvimento motor, cognitivo e afetivo das crianças. O mesmo percentual de professores classificaram ser "Muito Importante" os jogos lúdicos e as atividades recreativas enquanto conteúdo para as aulas na Educação Infantil.

Nota-se também, na tabela acima, que em relação à ludicidade e recreação como o conteúdo das aulas dentro das escolas pode 
acarretar benefícios para o desenvolvimento do ensino e aprendizagem da criança e quanto à sua importância dentro da escola, 100\% dos professores responderam que "sempre", como tambémque a ludicidade e recreação "Sempre" será de grande importância e pode trazer benefícios para o desenvolvimento da criança.

Segundo Salomão e Martini, (2007) a ludicidade é uma necessidade do ser humano em qualquer idade e não pode ser vista apenas como diversão, o seu princípio de iniciação esta relacionado ao desenvolvimento do aspecto lúdico, que facilita assim a aprendizagem, o desenvolvimento pessoal, social e cultural e colabora para a boa saúde mental e física, portanto diga-se que o lúdico e suas manifestações diferem-se de acordo com a cultura e a época que o mesmo está inserido existem três elementos que possibilitam a vivência por inteiro do ser humano em relação à prática lúdica, sendo eles: a possibilidade de criar, o lúdico e o lado humano de ser, permitindo expressão dos sentimentos do ser humano com ele próprio, como, também, dele com o mundo que o cerca e sua existência ao longo do desenvolvimento dos aspectos culturais.

Sendo assim, como exposto a atividade lúdica pode ser considerada como toda animação ou divertimento que tenha como objetivo proporcionar prazer e entretenimento a quem a pratica. No entanto, são tidas como atividades lúdicas todas aquelas ações que propiciem uma experiência completa do momento em que se pratica a mesma, associando-a ao ato, ao pensamento e ao sentimento do indivíduo. Portanto, a criança acaba por expressar-se, assimilando assim os conhecimentos e, por sua vez, construindo a sua realidade da escola em objetivo ao desenvolvimento psicológico, afetivo, cognitivo, motor e social da criança (GRILO, 2015).

Como caracterizado, nota-se que o lúdico pode ser uma atividade, cujos preceitos e estrutura vêm sendo constituído com um momento prazeroso de interação e aprendizagem, contribuindo assim, de maneira significativa no que diz respeito ao processo de socialização, expressão, construção do pensamento e comunicação (GRILO, 2015; SOUSA; SILVA, 2017). 
Neste contexto, estes resultados têm com prerrogativa demonstrar uma revisão de literatura a cerca de estudos envolvendo a ludicidade na Educação Infantil, como meio de esclarecer sua importância para o desenvolvimento do ensino e aprendizagem da criança. Busca-se, então, uma maior compreensão sobre o assunto o qual incidem sobre a prática da ludicidade no ambiente escolar e principalmente na educação infantil, tornando-se importante relatar aspectos relacionados à conceituação do lúdico e os preceitos da estrutura da atividade lúdica, o papel do professor da infância e a ludicidade utilizando o lúdico como recurso metodológico.

\section{Considerações finais}

Em respostaaos objetivos do estudo, pode-se concluir que a ludicidade nas aulas da Educação da Infantil é de grande importância no desenvolvimento da criança. Através das atividades lúdicas e recreativas aplicadas é possível ajudar a desenvolver a capacidade de assimilação do conteúdo proposto como forma de ensino e de aprendizagem da criança. Outros pontos primordiais são os aspectoscognitivos, afetivos e motores que, com a prática, tendem mutuamente a serem aprimorados no processo.

Sabe-se que na escola a ludicidade tem oportunidade de ser trabalhada de acordo com a idade da criança, conforme a sua cultura, aperfeiçoando assim o seu espaço com mais autonomia. É possível perceber que o conteúdo de atividades lúdicas utilizado como processo metodológico dentro da Educação Infantil traz possibilidade de o professor criar, no aluno, condições de equilíbrio e desenvolver a interdisciplinaridade.

Nesse contexto, o trabalho desenvolvido tanto por profissionais de Educação Física ou por Pedagogos deve prever a formação de base indispensável no desenvolvimento motor, afetivo e psicológico, dando oportunidade para que por meio de jogos, do esporte, da dança, da ginástica, da luta e de atividades lúdicas, possibilite a conscientização sobre o próprio corpo. De modo geral, a ludicidade ajuda em vários fatores, entre eles, auxilia no processo de apren- 
dizagem e em possíveis dificuldades encontradas no mesmo. No entanto, vale lembrar que, para tanto, é imprescindível considerar o fator "político", considerando a necessidade de verba para que se possam desenvolver projetos pedagógicos exemplares.

No entanto para que se possam obter resultados com maior prevalência recomendam-se a realização de outros estudos sobre a ludicidade e sua relação com o desenvolvimento da criança na educação infantil, na busca de obter uma associação entre os aspectos psicomotores e os externos que são propostos pelos professores para o desenvolvimento da criança que assim podem resultar e desencadear um bom rendimento, promovendo assim o avanço do conhecimento relacionado a esta temática de estudo.

\section{Referências}

BARBOSA, C. L. Educação Física Escolar da alienação à libertação. 1. Ed. Petrópolis: Vozes, 2007.

BARBOSA, C. L. A. Educação Física Escolar: as representações sociais. Rio de Janeiro: Shape, 2001.

BET'TI, M. Educação Física escolar: uma proposta de diretrizes pedagógicas. Revista Mackenzie de Educação Física e Esporte, Rio de Janeiro, v. 2, n. 04, p. 73-81, 2018.

BORBA, A. M. O brincar como um modo de ser e estar no mundo. In: BRASIL, Ministério da Educação. Secretaria de Educação Básica. Ensino Fundamental de nove anos: Orientações para a inclusão de crianças de seis anos de idade. 2. ed. Brasília, 2016.

DALLABONA, S. R.; MENDES, S. M. S. O Lúdico na Educação Infantil: Jogar, Brincar, uma forma de Educar. Revista de divulgação técnico-científica do ICPG, v. 1, n. 4, p. 1-19, 2015.

FERRAZ, O. L. Educação Física Escolar: Conhecimento e Especificidade a Questão da Pré-Escola. Revista Paulista de Educação Física, São Paulo, Suplemento 2, n. 1, p. 16-22, 1996.

FREIRE, J. B. Educação de corpo inteiro: teoria e prática da Educação Física. São Paulo: Scipione, 1997.

GAllardo, J. S. P.; OLIVEIRA, A. A. B.; ARAVENA, C. J. O. Didática da Educação Física: a criança em movimento: jogo, prazer e transformação. FTP, São Paulo, v. 03, n. 4, p. 1-22, $2018 .$. 
GRILO, A. P. S. E. A. O Lúdico na formação do professor. Universidade Federal da Bahia, Salvador, 2015.

IGNACHEWSKI, I. O Lúdico na formação do dducador. In: Rosa, Adriana (Org.). Lúdico e alfabetização., Curitiba: Juruá, v. 03, n. 2, p. 81-85, 2003.

KRAMER, S. Com a pré-escola nas mãos: uma alternativa curricular para a educação infantil. São Paulo: Ática, p. 1-203, 2009.

LEITE, S. R. M.; SILVA, A. T. T. Infância e ludicidade: a experiência do brincar na ludoteca. Grupo de Estudos e Pesquisa em Educação e Infância, Departamento de Educação da Universidade Estadual de Londrina, Londrina, 2015.

MARCONI, M. D.; LAKATOS, E. M. Fundamento de Metodologia Cientifica. São Paulo: Atlas S.A, p. 1-203, 2010.

MEINHARDT, A. E. A. Ludicidade: magia, encanto e aprendizagem. Disponível em: http://www.ideau.com.br/upload/artigos/art_38.pdf., 2009.

PAIANO, R. Possibilidades de orientação da prática pedagógica do profesor de educaçao física: situações de desprazer na opinião dos alunos. Revista Mackenzie de Educação Física e Esporte, São Paulo, 5, n. 1, p. 47-58, 2016.

ROMPKOVSKI, A. B. F.; SILVA, R. O papel da brincadeira no desenvolvimento infantil. In: ROSA, Adriana (Org.). Lúdico e alfabetização., Curitiba: Juruá, v. 2, n. 3, p. 44-53, 2003.

SALOMÃO, H. A. S.; MARTINI, M. A importância do lúdico na Educação Infantil: enfocando a brincadeira e as situações de ensino não direcionado. Revista de psicologia, v. 1, n. 2, p. 27-39, 2007.

SILVA, R. L. Lazer e gênero: suas relações com o lúdico. In: SCHWARTZ, Gisele Maria (Org.). Dinâmica lúdica: novos olhares. [S.1.]: Manole, 2004. p.111-129. p.

SOUSA, J. M.; SILVA, J. B. A psicomotricidade na educação infantil. Revista Eventos Pedagógicos, Mato Grosso do Sul, 4, n. 2, p. 1-12, 2017.

SPIGOLON, R. A importância do lúdico no aprendizado. Trabalho de conclusão de curso (Graduação) - Universidade Estadual de Campinas, Faculdade de Educação. Campinas, SP, 2006.

THOMAS, J. R.; NELSON, J. R. Métodos de Pesquisa em Atividade Física. $3^{\mathrm{a}}$. ed. [S.1.]: Artmed, 2002, 1-209 p.

Submetido em: 4-1-2021

Aceito em: 26-7-2021 